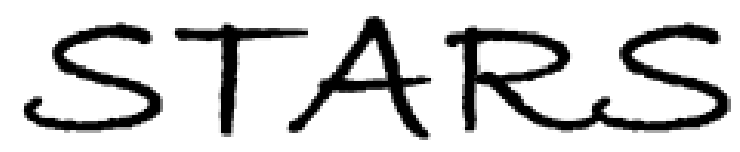

University of Central Florida

STARS

Faculty Bibliography 1980s

Faculty Bibliography

$1-1-1980$

\title{
Some New Worldwide Cloud-Cover Models
}

Steven J. Bean

University of Central Florida

Paul N. Somerville

University of Central Florida

Find similar works at: https://stars.library.ucf.edu/facultybib1980

University of Central Florida Libraries http://library.ucf.edu

This Article is brought to you for free and open access by the Faculty Bibliography at STARS. It has been accepted for inclusion in Faculty Bibliography 1980 s by an authorized administrator of STARS. For more information, please contactSTARS@ucf.edu.

\section{Recommended Citation}

Bean, Steven J. and Somerville, Paul N., "Some New Worldwide Cloud-Cover Models" (1980). Faculty Bibliography 1980s. 49.

https://stars.library.ucf.edu/facultybib1980/49

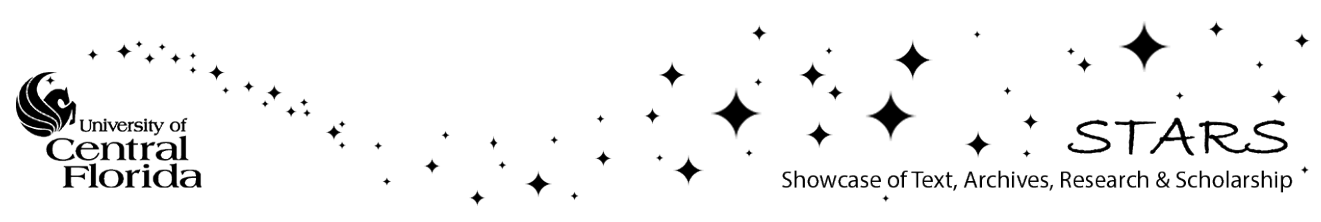




\title{
Some New Worldwide Cloud-Cover Models
}

\author{
Steven J. Bean and Paul N. Somerville \\ Department of Mathematics and Statistics, University of Central Florida, Orlando, FL 32816
}

(Manuscript received 19 May 1980, in final form 1 April 1981)

\begin{abstract}
Using daily measurements of day and night infrared, and incoming and absorbed solar radiation obtained from a TIROS satellite over a period of approximately 45 months, and integrated over $2.5^{\circ}$ latitudelongitude grids, the proportion of cloud cover over each grid each day was derived for the entire period. For each of four 3-month periods, for each grid location, estimates $a$ and $b$ of the two parameters of the best-fit beta distribution were obtained. The $(a, b)$ plane was divided into a number of regions. All the geographical locations whose $(a, b)$ estimates were in the same region in the $(a, b)$ plane were said to have the same cloud cover type for that season. For each season, the world is thus divided into separate cloud-cover types.
\end{abstract}

\section{Introduction}

The purpose of this study was to develop a model for worldwide cloud cover using a satellite data set containing infrared measurements. Some earlier models using primarily ground-based cloud observations are described in Barnes et al. (1968), Greaves et al. (1971) and Falls (1974). For some fairly large areas of the world, ground-based observations either are very sparse, or they do not exist. Models relying on such observations require a number of assumptions, including on occasion that a region is essentially like its antipodal location.

The present study uses a data set from a TIROS satellite, which has recently become available. The data set contains day and night infrared, and incoming and absorbed solar radiation measurements on a $2.5^{\circ}$ latitude-longitude grid covering a 45 -month period of record. A description of the data set is given in Gruber and Winston (1978). These data were converted into estimates of cloud cover. For each of the four seasons, the global area was then classified into homogeneous cloud-cover regions.

Worldwide cloud-cover models are useful for studying relationships between cloudiness, precipitation and the earth radiation budget.

\section{Conversion of satellite measurements to cloud cover}

A major initial task was to derive cloud-cover estimates from the satellite infrared data. The method used in this investigation follows the suggestions of Gray (1978).

Albedo is defined as the reflective power, or the fraction of incident light that is reflected by a surface or body. Included in the satellite data are the amount of incoming solar radiation $I_{\text {in }}$ and the amount of absorbed solar radiation $I_{\mathrm{ab}}$. The satellite-observed albedo $A$, is estimated by

$$
A=\left(I_{\text {in }}-I_{\text {ab }}\right) / I_{\text {in }} \text {. }
$$

If the earth's surface absorbed all solar radiation, then the cloud cover might be taken simply as $1-A$ (assuming also that clouds reflect all solar radiation). Different parts of the earth's surface, however, have differing radiances. For example, the albedo of the ocean is $\sim 5 \%$ ( $95 \%$ of the solar radiation being absorbed), while the Sahara desert reflects $\sim 40 \%$ of the solar radiation reaching it.

To determine cloud cover, the background radiation of the region of the earth of interest was needed. To obtain this, for a given season and a specified location, $A$ was calculated from (1) for every day of a season and the minimum value, $A_{\min }$ observed. This minimum value should occur on the day of least (hopefully near zero) cloud cover. If $r$ is the reflectance of the clouds and $x$ is the fraction of cloud cover, then the basic formula may be written as

$$
A=x r+(1-x) A_{\text {min }},
$$

from which $x$, the fraction of cloud cover, is given by

$$
x=\left(A-A_{\min }\right) /\left(r-A_{\min }\right) .
$$

This formula requires a knowledge of the cloud reflectance $r$.

A way to estimate $r$ is by observing the difference between the earth's surface temperature and the temperature equivalent of the satellite-observed daytime infrared reading (denoted by $I R_{D}$ ). The radiance of the $I R_{D}$ by Stefan's law is equal to 5.75 $\times 10^{-8} T^{4}\left(\mathrm{~W} \mathrm{~m}^{-2}\right)$, where $T$ is the temperature equiv- 
TABLE 1. Shapes of the beta probability density function for different $a$ and $b$ parameters.

\begin{tabular}{|c|c|c|}
\hline Shape & Cloud-cover characteristics & Parameters \\
\hline Mound & $\begin{array}{l}\text { Seldom very clear or very } \\
\text { cloudy }\end{array}$ & $a>1 \quad b>1$ \\
\hline $\mathbf{J}$ & Most frequently cloudy & $a>1 \quad b<1$ \\
\hline Reverse J & Most frequently clear & $a<1 \quad b>1$ \\
\hline $\mathbf{U}$ & $\begin{array}{l}\text { Most frequently very clear } \\
\text { or very cloudy }\end{array}$ & $a<1 \quad b<1$ \\
\hline Uniform $(0,1)$ & $\begin{array}{l}\text { Equal chance of clear, } \\
\text { cloudy or partly cloudy }\end{array}$ & $a=1 \quad b=1$ \\
\hline
\end{tabular}

alent in degrees kelvin. Putting $z=$ (surface temperature $-T$ ), (units degree kelvin), the following relationship was derived using Gray (1978):

$$
r=-0.000265 z^{2}+0.0295 z+0.10 .
$$
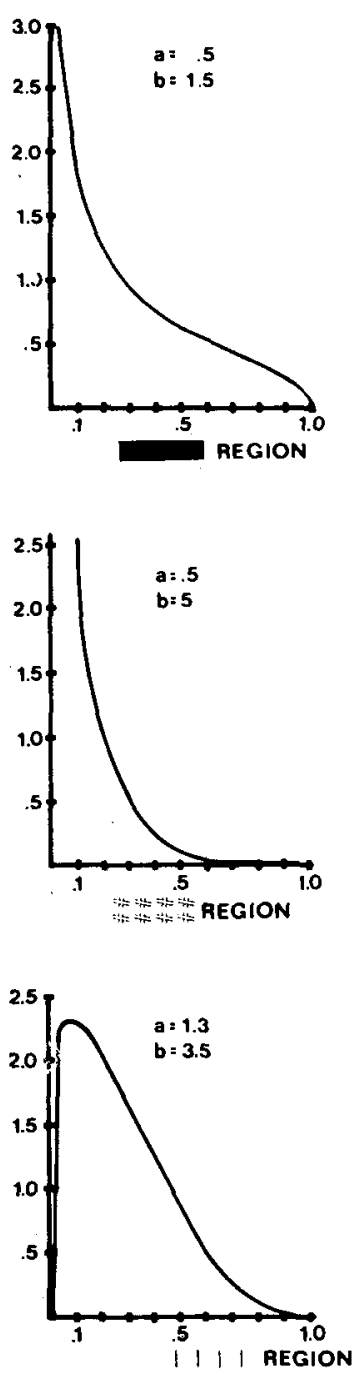
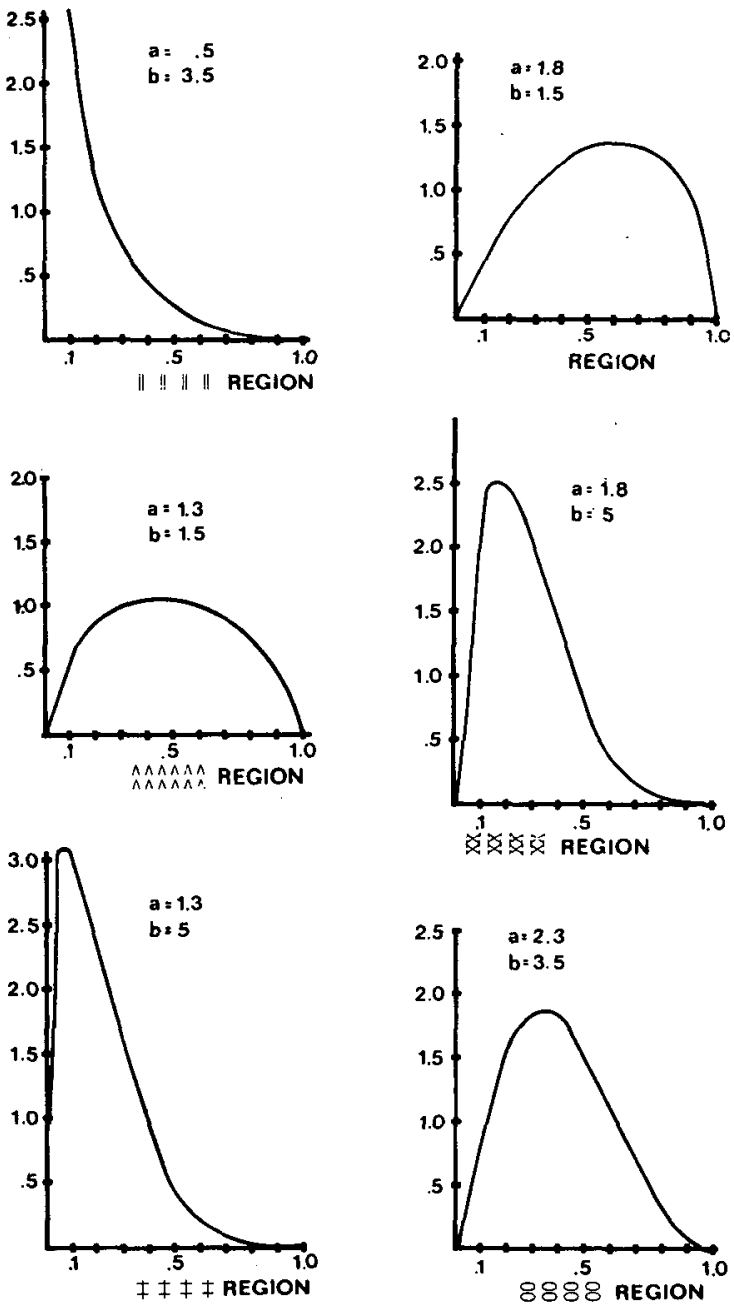
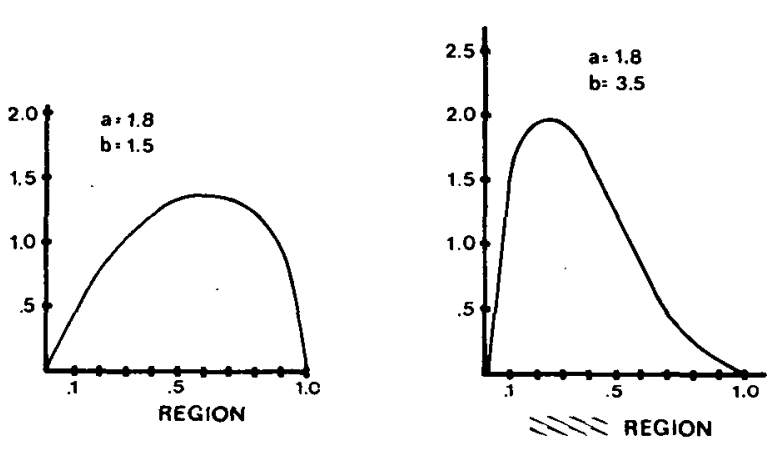

FIG. 1. Typical beta curves associated with regions in Fig. 3.
A surface temperature of $30^{\circ} \mathrm{C}$ for latitudes within $25^{\circ}$ of the equator and $-5^{\circ} \mathrm{C}$ for latitudes within $25^{\circ}$ of the pole was used. Interpolations were used for intermediate latitudes.

Using this method, the proportion of cloud cover was calculated for each day of the year over the 4-year period covering the entire globe. The data for the four 3-month periods were considered separately and an individual cloud-cover model developed for each.

A possible criticism of this investigation is that it is based on derived cloud-cover estimates. It should be emphasized that both ground-based cloud observations and observations from satellite photography result in estimates. It is conjectured that those variables which are not well defined in the $I R$ to cloud cover conversion procedure will have small contributions to climatic modeling of the clouds over the entire season. For a specific day and area the 
TABLE 2. Global $(a, b)$ frequencies for December, January and February.

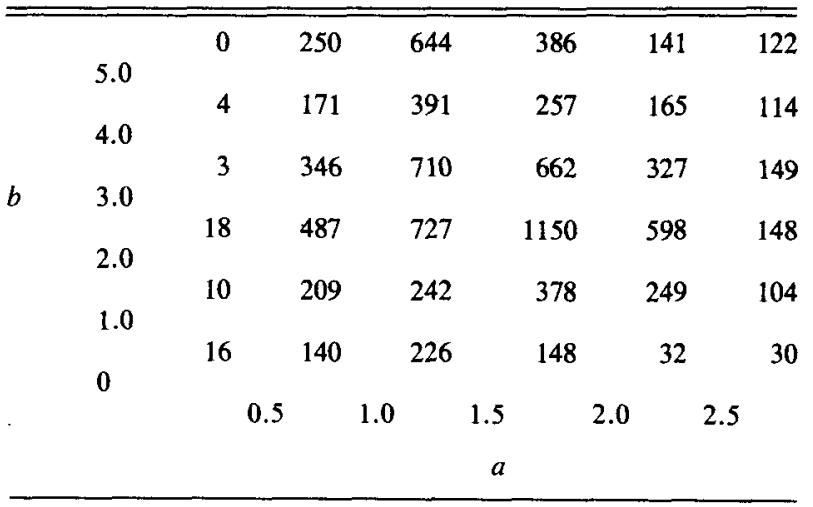

preceding procedure may not be entirely satisfactory for synoptic cloud-cover analysis. It should be noted that, because of the orbit of the TIROS satellite, the estimates in the near polar regions may be somewhat degraded.

\section{A probabalistic model for cloud cover}

The proportion of cloud cover over any grid square is a random variable which has some probability distribution associated with it. Falls (1974) found that the beta distribution could be used to represent the probability distribution of the proportion of cloud cover. Henderson-Sellers (1978) has also found the beta distribution useful as a model for the probability distribution of the proportion of cloud cover. The beta probability density function with parameters $a$ and $b$ is given by

$$
f(x)=\frac{\Gamma(a+b)}{\Gamma(a) \Gamma(b)} x^{a-1}(1-x)^{b-1},
$$

for $0 \leqslant x \leqslant 1, a>0, b>0$.

The beta probability density function can assume a variety of shapes. It can be mound-shaped, Ushaped, or J-shaped with varying amounts of skewness. Table 1 shows the relationship between the $a$
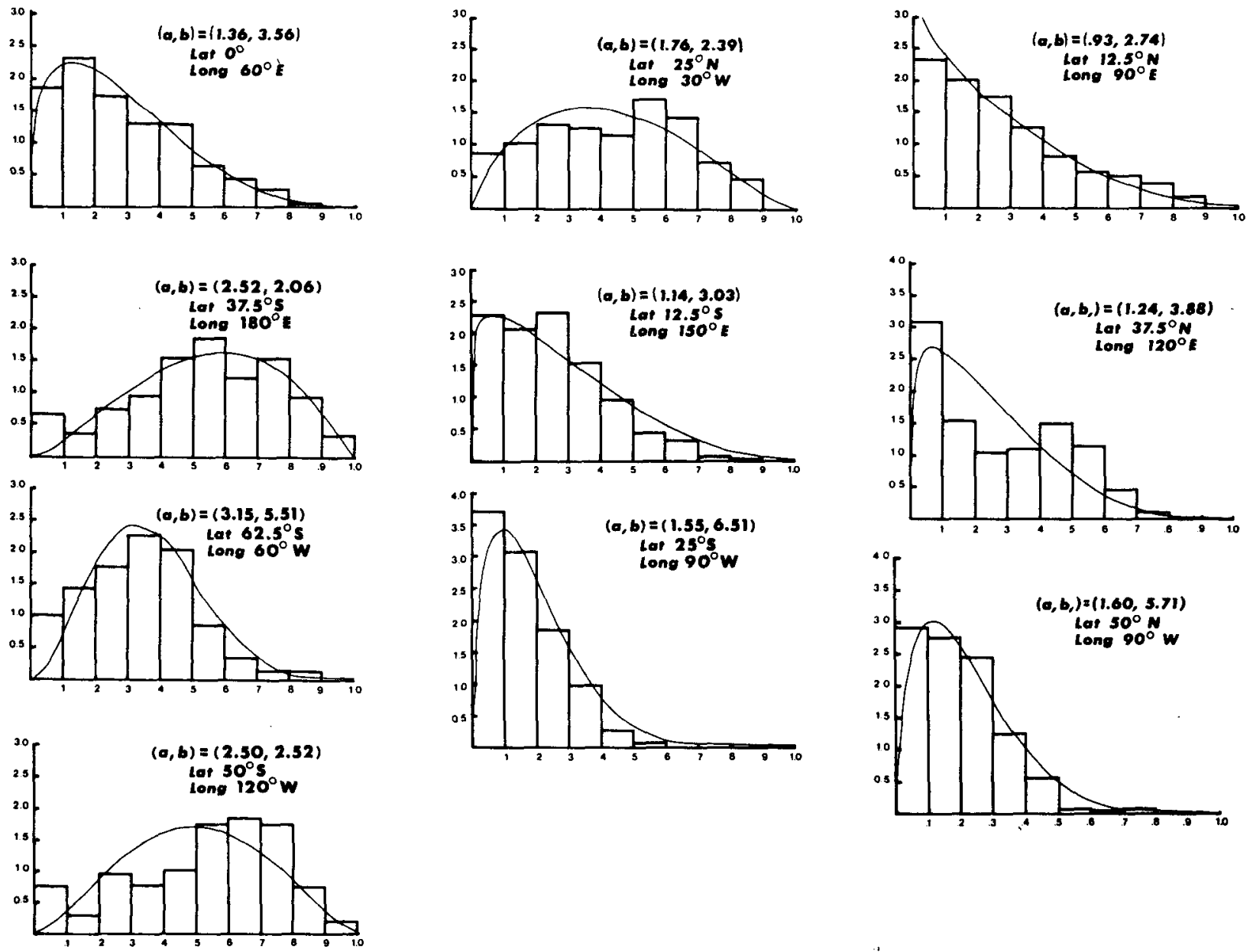

FIG. 2. Histograms of the portion of cloud cover with beta curves superimposed. 


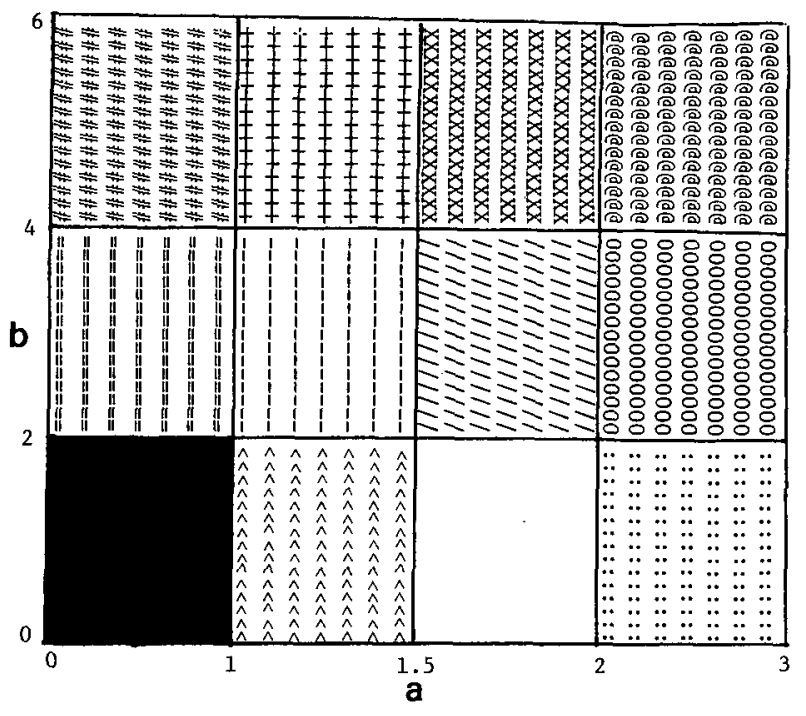

Fig. 3. Key for recoded homogeneous cloud-cover regions map.

and $b$ parameters and the shape of the frequency curve.

To check the adequacy of fitting the beta distribution, a grid location was selected at random from latitude circles $12.5^{\circ}$ apart, beginning with $50^{\circ} \mathrm{N}$ latitude and extending to $62.5^{\circ} \mathrm{S}$ latitude. A histogram was constructed for each selected location for the months of December, January and February for the four years of data ( $\sim 350$ observations). Using the method of moments, estimates of $a$ and $b$ were obtained for the parameters of the beta distribution and the corresponding beta probability density functions superimposed on the histograms. These graphs are illustrated in Fig. 2.

\section{A worldwide cloud-cover model using the beta dis- tribution}

The $(a, b)$ parameters of the beta distribution give a good deal of information about the cloud-cover characteristics of a given location. Table 2 gives a table showing the frequencies of occurrence of $(a, b)$ pairs for the 10224 grid points on the globe for the three-month period of December, January and February.

The 36 regions in the $(a, b)$ plane from the frequency histogram for global $(a, b)$ values form a basis for determining homogeneous cloud cover regions. Grid points on the globe which have $(a, b)$ parameters falling in the same block have very similar cloud-cover characteristics. For a preliminary cloud-cover model, each grid point on the globe was assigned to one of 36 groups depending on the block in which $(a, b)$ falls. A FORTRAN program was used to label each grid point with $0-9$ or $A-Z$ depending on the group the grid point fell into. These labels were printed in a rectangular array maintaining the latitude and longitude position of each point. This procedure resulted in a map of the globe containing a large number of contiguous regions which have the same basic cloud-cover characteristics. These maps were simplified by combining several of the 36 blocks and recoding the maps. The recoded maps are shown in Figs. 4-7. The key for the recorded maps is given in Fig. 3. The various regions on the map may be interpreted by considering a typical frequency distribution associated with the printed symbol. These distributions are given in Fig. 1.

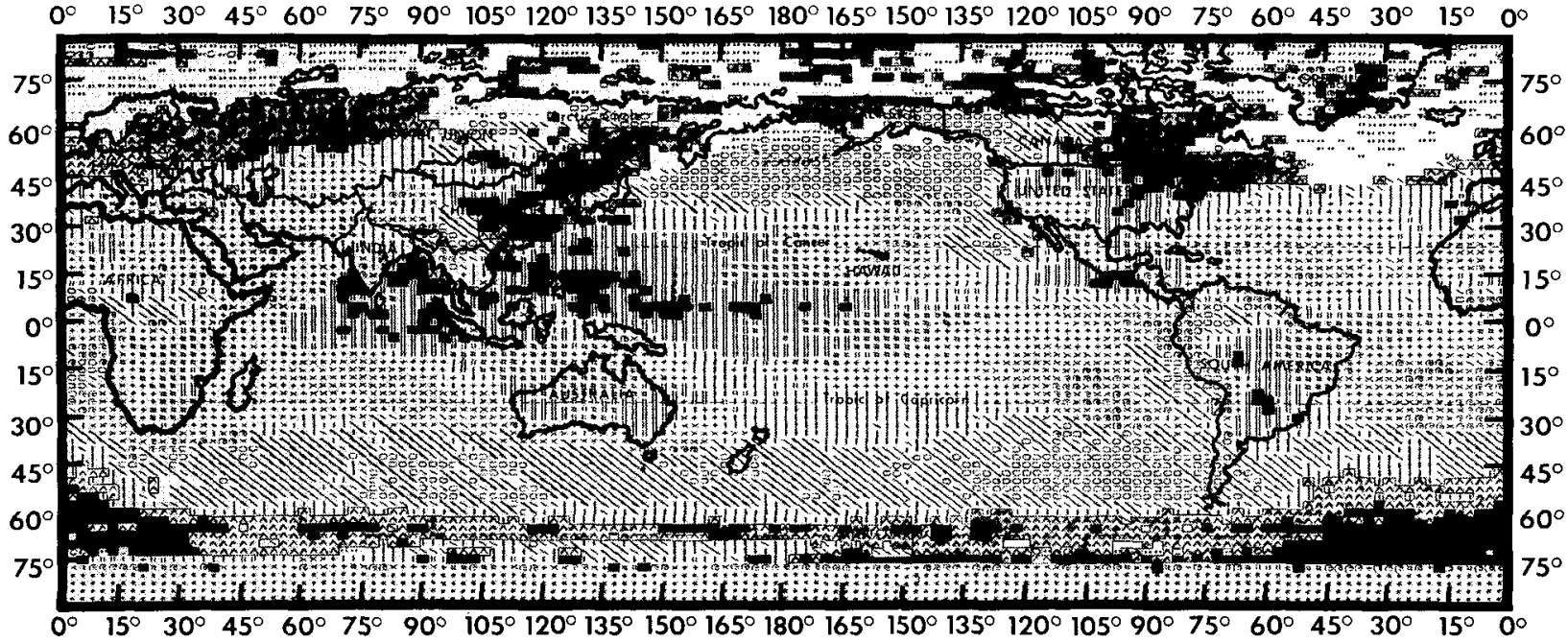

FIG. 4. Global cloud-cover classification based on $(a, b)$ parameters of the beta distribution (June, July, August). 


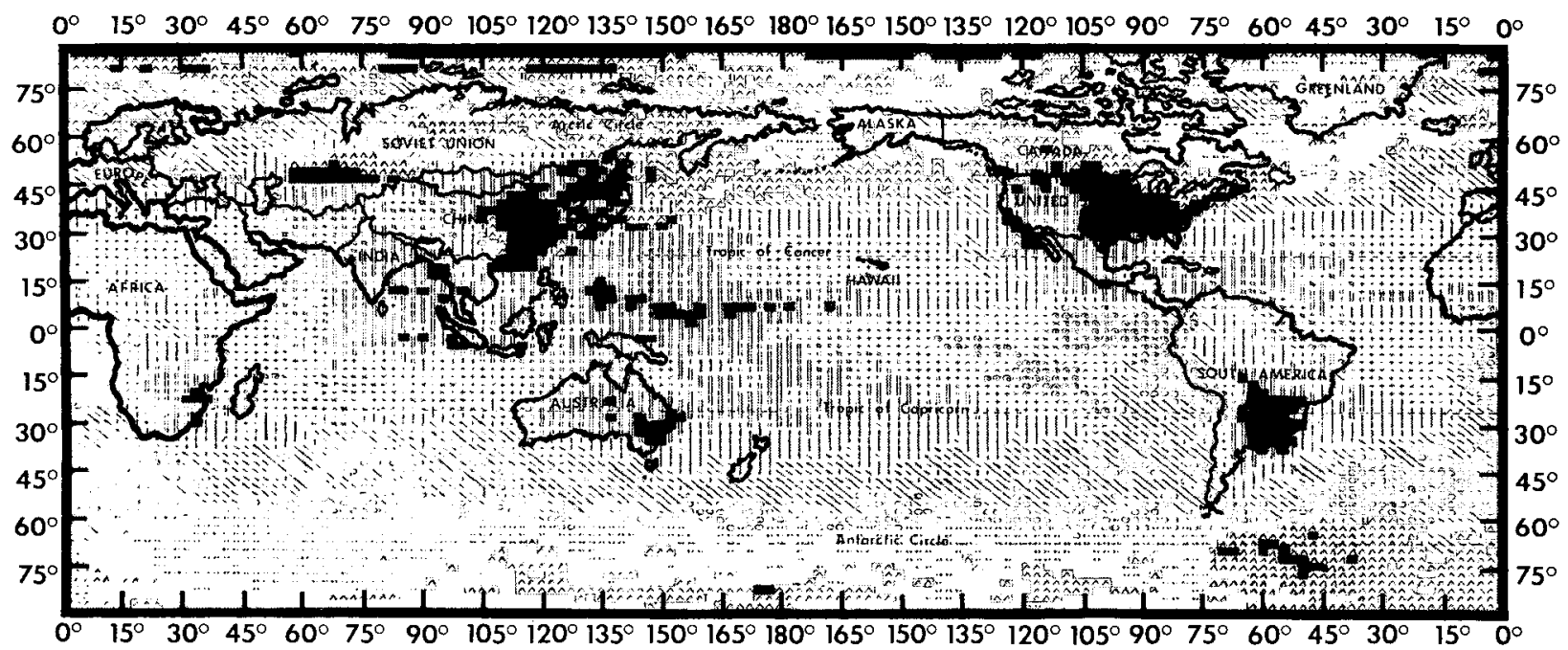

Fig. 5. Global cloud-cover classification based on $(a, b)$ parameters of the beta distribution (September, October, November).

\section{Conclusions and recommendations}

The current cloud-cover model illustrates a useful objective methodology for cloud-cover classification. The developed maps can provide useful information regarding the cloud cover characteristics for any particular location on the globe. This is particularly useful in that the practicing climatologist can obtain a great deal of cloud-cover information without going through large volumes of data.

There are problems with the current cloud cover model. The most obvious of these is the lack of data. To make a good climatological model a reasonably long record length is required. The satellite data available for this study comprise approximately
45 months. This is sufficient for some model development, but a longer period of record would be desirable. Also, temporal persistence cuts down on the actual number of independent cloud cover observations. Another problem is that the cloud-cover used in the model is derived. This is not to say that the cloud-cover values used are not accurate, but the derived cloud cover should be compared with some independently observed cloud cover. It should be noted that any type of cloud-cover measurement will have some degree of error associated with it.

The topic of error analysis in the estimation of the parameters $(a, b)$ was not covered for several reasons. There are several types of errors which made

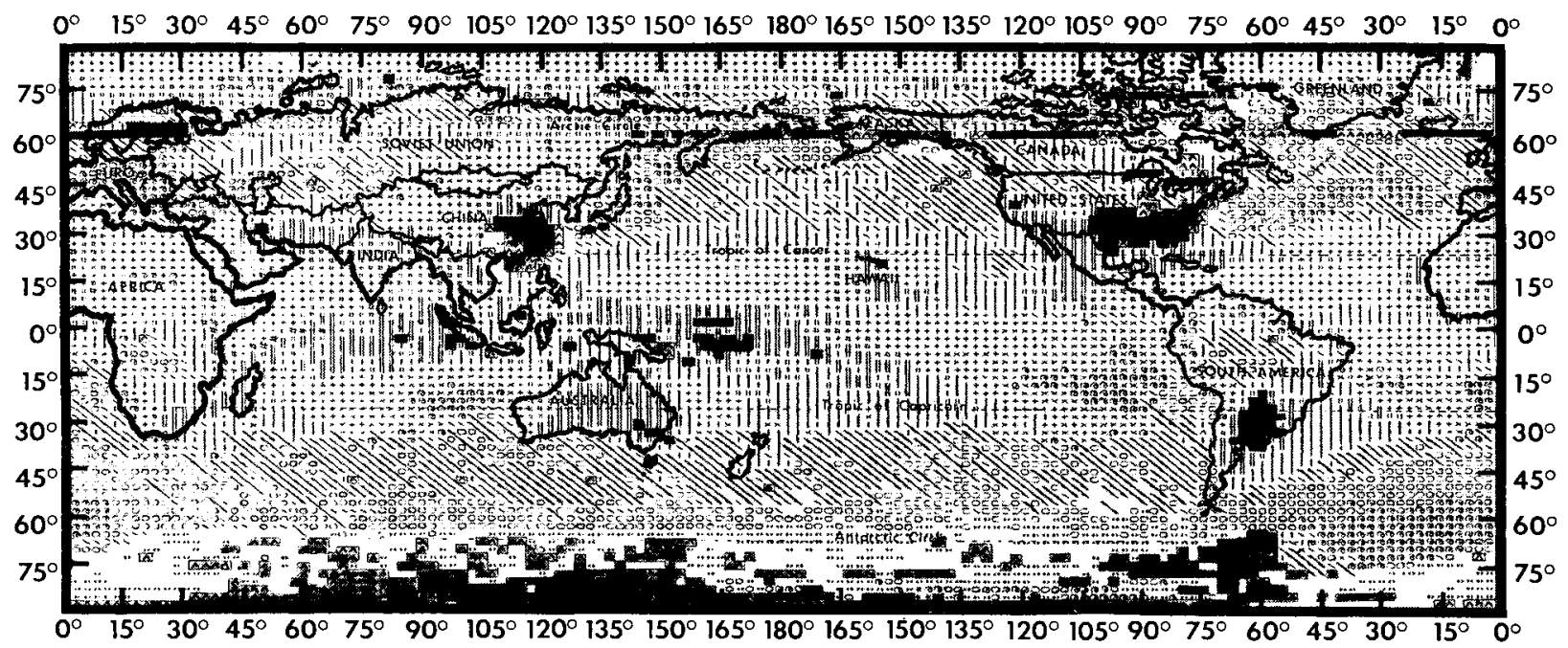

FIG. 6. Global cloud-cover classification based on $(a, b)$ parameters of the beta distribution (December, January, February). 


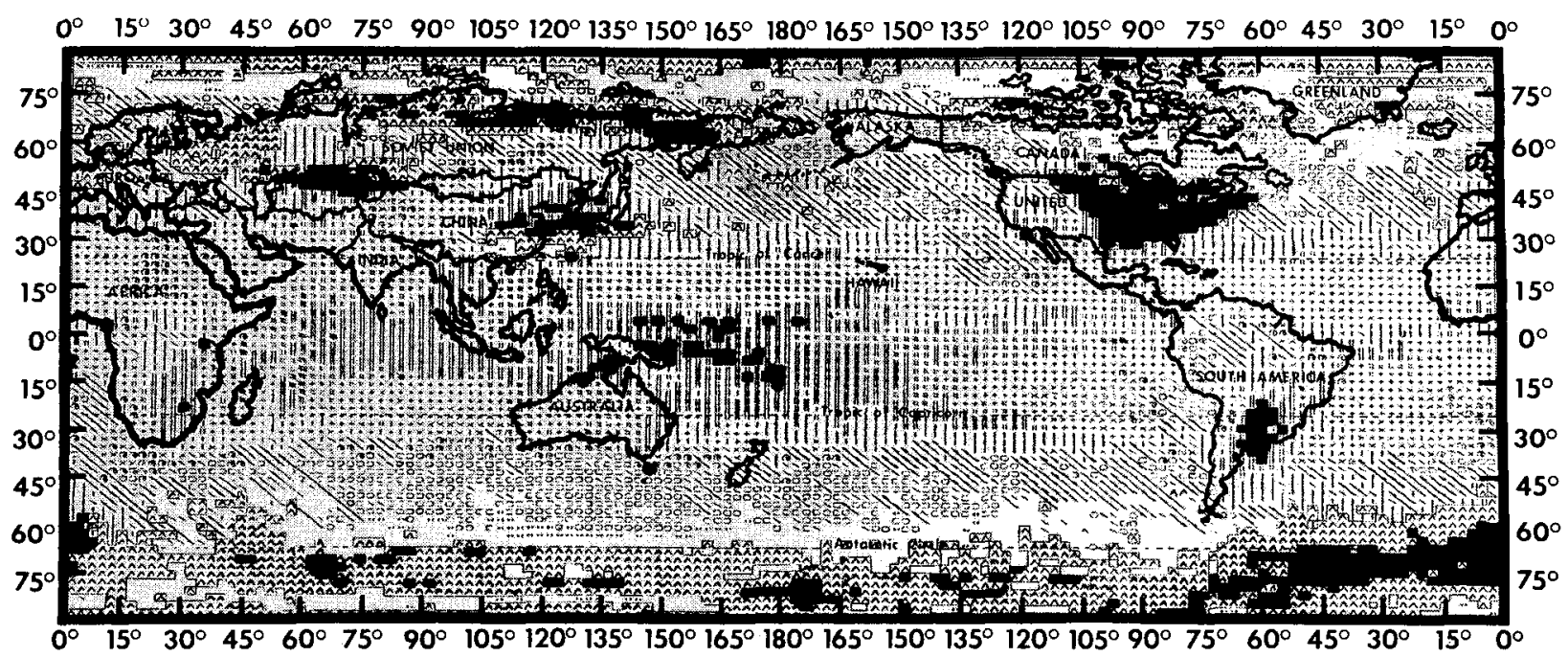

FIG. 7. Global cloud-cover classification based on $(a, b)$ parameters of the beta distribution (March, April, May).

the problem quite complex. First, as previously mentioned, there is an unknown error component in the derived cloud cover itself which may vary from place to place. Also, there is error in recorded satellite measurements. The cloud-cover values have a temporal correlation which is not fully known. The short length of the record certainly contributes to the error (the degree of error depends on the temporal persistence of cloud cover and the long-term cyclic behavior of cloud cover). Another factor is that the satellite measurements were taken for a given grid location at the same time each day.

It is worth remarking that even with the abovementioned errors, it is still possible to use the data at hand to classify areas of the globe into homogeneous cloud-cover regions. The methodology is sound, and the presently developed models should give a good overall picture of global cloud-cover characteristics.

The above comments lead to three major recommendations. First, the derived cloud cover should be verified using some independent measurements. Second, spatial and temporal persistence of cloud cover need to be investigated. Third, the model should be updated with a longer length record.

Acknowledgment. This research was sponsored in part under Contract NAS-8-33071 National Aeronautics and Space Administration, Marshall Space Flight Center.

\section{REFERENCES}

Barnes, J. C., A. H. Glase, P. E. Sherr and J. H. Willand, 1968: Worldwide cloud cover distribution for use in computer simulations. NASA Contractor Rep. CR-61226, 275 pp.

Bean, Steven J., and Paul, N. Somerville, Some new worldwide cloud cover models, 1979: Final Report, Contract NAS 833071, Marshall Space Flight Center, 34 pp.

Greaves, J. R., D. B. Spiegler and J. H. Willand, 1971: Development of a global cloud cover model for simulating earthviewing space missions. NASA Contractor Rep. CR-61345, $141 \mathrm{pp}$.

Falls, L. W., The beta distribution, 1974: A statistical model for world cloud cover. J. Geophys. Res., 79, 1261-1264.

Gruber, A., and Jay S. Winston; 1978: Earth-atmosphere radiative heating based on NOAA scanning radiometer measurements. Bull. Amer. Meteor. Soc., 59, 1570-1573.

Henderson-Sellers, A., 1978: Surface type and its effect upon cloud cover, 1978: A climatological investigation. J. Geophys. Res., 83, 5057-5062. 